\title{
Trichloromethane fraction of Incarvillea compacta induces lytic cytotoxicity and apoptosis in Epstein-Barr virus-positive gastric cancer AGS cells
}

Lijing Zhang, Haifeng Wu, Guibo Sun, Xudong Xu, Xiaobo Sun and Li Cao*

\begin{abstract}
s
Background: Incarvillea compacta Maxim. has been used to treat stomach disease in Tibet for many years. The objectives of this study were to explore the anti-cancer ability of trichloromethane fraction of I. compacta Maxim. roots (IC-TCL, R2) in EBV positive AGS cancer cells and its effects on cell cycle arrest, apoptosis and lytic induction.

Methods: MTT and trypan blue assays were to detect the inhibitory effects of different fraction in different cell lines. Hoechst 33342 staining, Annexin V-PE/7-AAD staining and DIOC 6 staining were used to detect the apoptosis induction effects of R2. Western blot experiments were used to detect the expression of apoptosis related proteins $\mathrm{BAX}$ and $\mathrm{BCl}-2$, EBV lytic related proteins BZLF1 and BMRF1, cell cycle regulation related proteins Cyclin D1 and RB after R2 treatment. Cell cycle arrest was analyzed by flow cytometry.

Results: MTT and trypan blue assays revealed that R2 could significantly reduce cell viability in a dose-dependent manner in EBV positive AGS cells compared with non-EBV infected AGS and other cancer cell lines, whereas n$\mathrm{BuOH}$ and $\mathrm{H}_{2} \mathrm{O}$ fractions showed non-inhibitory effects in tested cancer cells. R2 could decrease mitochondrial membrane potential and the expression of $\mathrm{BCl}-2$, while increase the expression of BAX. R2 could also induce EBV lytic replication by activating mRNA levels of BZLF1, BRLF1 and BMRF1. Protein expressions of BZLF1 and BMRF1 were also increased after R2 treatment. Cell cycle analysis showed that R2 treatment could induce G0/G1 phase arrest. The expression of Cyclin D1 decreased, while Rb increased.
\end{abstract}

Conclusions: These results demonstrated that R2 could inhibit the proliferation of AGS-EBV cancer cells by inducing EBV lytic replication, apoptosis and GO/G1 arrest, through the regulation of related proteins. Therefore, R2 could be used as a potential treatment in AGS-EBV cells.

Keywords: Gastric cancer, Incarvillea compacta, EBV, Cell cycle, Apoptosis

Abbreviations: DMEM, Dulbecco's Modified Eagle's Medium; EBV, Epstein-Barr virus; FBS, Fetal bovine serum; I. compacta, Incarvillea compacta; IC-BT, I. compacta n-BuOH fraction; IC-ET, I. compacta ethanolic fraction; IC-R, I. compacta $\mathrm{H}_{2} \mathrm{O}$ fraction; IC-TCL R2, Trichloromethane fraction of Incarvillea compacta Maxim. Roots; LCL, Lymphoblastoid cell lines; MTT, 3-(4,5-dimethylthiazol-2-yl)-2, 5-diphenyltetrazolium bromide; PI, Propidium iodide; RT-PCR, Real-time polymerase chain reaction; U-HPLC, Ultra-high performance liquid chromatography

\footnotetext{
*Correspondence: Icao@implad.ac.cn

Institute of Medicinal Plant Development, Chinese Academy of Medical

Sciences \& Peking Union Medical College, 151 Malianwa North Road, Haidian

District, Beijing 100193, China
}

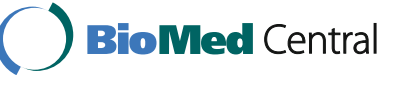

(c) 2016 The Author(s). Open Access This article is distributed under the terms of the Creative Commons Attribution 4.0 International License (http://creativecommons.org/licenses/by/4.0/), which permits unrestricted use, distribution, and reproduction in any medium, provided you give appropriate credit to the original author(s) and the source, provide a link to the Creative Commons license, and indicate if changes were made. The Creative Commons Public Domain Dedication waiver (http://creativecommons.org/publicdomain/zero/1.0/) applies to the data made available in this article, unless otherwise stated. 


\section{Background}

Gastric cancer was the third leading cause of global cancer deaths, causing a major health issue [1]. In recent years, with the development of tumor molecular biology techniques and understanding of pathogenesis, the molecular targeted therapies have been developed according to the reveal of oncogenic pathways [2-4]. Hence, there is a need to increase the efficacy of treatment and to reduce the side effects in gastric cancer therapy. Approximately ten percent of gastric cancer was infected with Epstein-Barr virus (EBV) [5]. EBV is a member of the $\gamma$-herpesvirus family which infects $90 \%$ of the world population [6]. The EBV life cycle includes latent and lytic form [7]. EBV persists in EBV positive malignancies as latent form; when the lytic cycle of EBV was activated, larger numbers of lytic proteins are expressed at high levels [27]. Lytic EBV replication damages the host cancer cells, which provides a potential therapeutic target for EBV associated cancers [28, 29]. The switch from latent to lytic EBV infection is mediated by expression of the two EBV immediate-early viral proteins, BZLF1 and BRLF1, which could activate the complete cascade of lytic viral gene expression $[8,9]$. These proteins activate the viral early genes, resulting in a cascade of events that lead to the activation of lytic replication. For the lytic form of EBV infection, the host immune responses were triggered against EBV and the host cancer cell may be killed [10]. EBV-associated malignancies generally have only a very low level of lytic EBV gene expression without chemotherapy [11]. Several therapeutic strategies could induce the lytic form of EBV infection by activating EBV lytic genes for tumor cells killing have been reported [12, 13]. For example,Romidepsin showed the ability to activate the lytic cycle of EBV and lead to cell death in EBV positive gastric cancer cells [14]. Taking together, these findings suggested that EBV itself could serve as a target for the killing of tumor cells.

Plants with various curative properties have received attentions in the area of pharmacology [15] Medicinal plants have played important roles in anticancer drug discovery [24]. Natural products have been involved in the development of approximately $75 \%$ of anticancer agents from 1981 to 2010 [16]. Therefore, exploring the possible mechanism of bioactivities of traditional used plants could promote the development of pharmaceutical products. Incarvillea belongs to the family Bignoniaceae, genus Incarvillea. Incarvillea compacta Maxim. is a perennial herb mainly distributed in Tibet, which has been traditionally used for treating dyspepsia and gastralgia for centuries [17]. So far, there have been studies on the chemical composition of other species of genus Incarvillea [18-21], which show antioxidant activities and life span prolonging, inhibitory effects on multiple kinase targets and their downstream pathways activated by solar UV in vitro and in vivo $[25,26]$. However, no pharmacological studies in stomach disorder treatment are available so far. Besides, the potential value of the herb in treating gastric cancer should not be ignored. Our previous phytochemical investigations on the species disclosed the presence of phenylethanoid glycosides in n-butyl alcohol fraction exhibiting hepatoprotective activity [22]. Thus, the present study was initiated to investigate anticancer effects of $I$. compacta.

In this study, we analyzed the cytotoxic effects of various fractions of $I$. compacta in stomach (AGS, AGSEBV, BGC-823), EBV-transformed B-cell lines (lymphoblastoid cell lines, LCL), liver (HepG-2), leukemia (K562), cervix (HeLa), lung (A549) and prostate (PC3 and DU145) cancer cells. The most effective fraction (trichloromethane fraction, IC-TCL, R2) in AGS-EBV cells growth inhibition was further evaluated for the induction of apoptosis, EBV lytic, and cell cycle arrest. We confirmed that R2 induce the expressions of EBV lytic genes in AGS-EBV cells and EBV-transformed B-cell lines (LCL), resulting in EBV-positive cells death in vitro. These findings indicated that $\mathrm{R} 2$ may be used as a novel agent in treating EBV-positive tumors.

\section{Methods \\ Plant materials}

I. compacta roots were collected in Huzhu County, Qinghai Province, China in July 2013, and identified by Prof. Xiao-Feng Zhang of the Department of Tibetan medicines, Northwest Institute of Plateau Biology, Chinese Academy of Sciences. A voucher specimen (NO. 130718) was deposited at the Key Laboratory of Bioactive Substances and Resource Utilization of Chinese Herbal Medicine, Ministry of Education, Institute of Medicinal Plant Development, Peking Union Medical College and Chinese Academy of Medical Sciences.

\section{Preparation of plant extract and fraction}

Dried and coarsely powered plant roots material of $I$. compacta $(1.1 \mathrm{~kg})$ was extracted three times with $90 \%$ ethanol $(3 \times 3 \mathrm{~L})$ at room temperature. Removal of the ethanol under reduced pressure yielded the I. compacta ethanolic extract (IC-ET). The practical yield of IC-ET was $8.90 \%$. The IC-ET (90 g) was suspended in distilled water $(1 \mathrm{~L})$ and then the suspension was partitioned with trichloromethane and $\mathrm{n}-\mathrm{BuOH}$, successively, yielding the trichloromethane fraction (IC-TCL), the n-BuOH fraction (IC-BT), and the $\mathrm{H} 2 \mathrm{O}$ fraction (IC-R). Each fraction was concentrated using rotary evaporator in vacuum, and completely dried. The yield of IC-TCL, IC-BT, and IC-R was $24.4 \%, 36.7 \%$, and $33.3 \%$, respectively. For biological assays, IC-TCL, IC-BT, and IC-R 
were dissolved in pure dimethyl sulfoxide and subjected to serial dilution so that the final concentration of DMSO in solution was less than $1 \%$.

\section{Instrumentations and analytical conditions Ultra-high performance liquid chromatography (U-HPLC)} Chromatography was performed on a Dionex UltiMate 3000 U-HPLC system consisted of an auto-sampler, a quaternary pump, and a column oven (Thermo, Markham, Ontario, Canada). The chromatographic separation was performed on a Waters Acquity BEH C18 column $(2.1 \mathrm{~mm} \times 100 \mathrm{~mm}, 1.7 \mu \mathrm{m}$, Waters Corporation, Milford, MA). The mobile phase was comprised of $5 \mathrm{mM}$ ammonium formate in water (solvent A) and $5 \mathrm{mM}$ ammonium formate in methanol (solvent B) at a flow rate of $0.3 \mathrm{~mL} / \mathrm{min}$. The gradient elution program was as follows: $5 \% \mathrm{~B}-25 \% \mathrm{~B}$ at $0-2 \mathrm{~min} ; 25 \% \mathrm{~B}-100 \% \mathrm{~B}$ at 2-30 min; $100 \%$ B - $100 \%$ B at 30-35 min. The column oven temperature and the auto-sampler temperature were maintained at $30{ }^{\circ} \mathrm{C}$ and $4{ }^{\circ} \mathrm{C}$, respectively. The sample injection volume was $5 \mu \mathrm{L}$.

\section{Mass spectrometer}

QExactive Orbitrap FTMS mass spectrometer equipped with an electrospray ionization (ESI) source (Thermo, Markham, Ontario, Canada) was connected to the UHPLC system via an electro spray ionization source (ESI) interface. The ESI source was operated in a positive ionization mode at a capillary voltage of $3.5 \mathrm{kV}$. Nitrogen was used as the desolvation gas $(600 \mathrm{~L} / \mathrm{h})$ and cone gas $(50 \mathrm{~L} / \mathrm{h})$. The temperatures of the source and desolvation were set at 150 and $400{ }^{\circ} \mathrm{C}$, respectively. $\mathrm{Ni}-$ trogen was used as the collision gas, and the collision energy was $14 \mathrm{eV}$.

\section{Reagents and antibodies}

Dulbecco's Modified Eagle's Medium (DMEM), Ham's F12 medium, trypsin, penicillin, streptomycin, fetal bovine serum (FBS) were purchased from Gibco (CA, USA), and 3-(4,5-dimethylthiazol-2-yl)-2, 5-diphenyltetrazolium bromide (MTT), DMSO, Hoechst 33342, $\mathrm{DIOC}_{6}$, RNase A, propidium iodide (PI), Trizol and trypan blue were purchased from Sigma-Aldrich (MO, USA). Dihydroethidium was bought from Beyotime Biotech (Jiangsu, China). The Annexin V-PE/7-AAD apoptosis detection kit was obtained from KeyGEN Biotech (Jiangsu, China). Antibodies against Bax, Bcl-2, Cyclin D1, BZLF1 and BMRF1 were obtained from Santa Cruz Biotechnology (CA, USA). Bax ((6A7) sc-23959) is a mouse monoclonal antibody raised against the $\mathrm{N}$-terminal residues $12-24$ common to human, mouse and rat Bax protein. Bcl-2 ((C-2) sc-7382) is a mouse monoclonal antibody raised against amino acids 1-205 of Bcl-2 of human origin. Cyclin D1 ((H-295) sc-753) is a rabbit polyclonal antibody raised against amino acids 1-295 representing full length cyclin D1 of human origin. EBV Ea-D ((1108-1) BMRF1, sc-69679) is a mouse monoclonal antibody raised against affinity purified early antigen polypeptides from induced Raji cells precipitated with African Burkitt's lymphoma sera. EBV ZEBRA ((BZ1) BZLF1, sc-53904) is amousemonoclonal antibodyraised against full-length recombinant EBV ZEBRA protein. Antibodies against $\mathrm{Rb}$, and $\beta$-actin were purchased from Cell Signaling Technology (MA, USA). Rb (4H1) Mouse mAb \#9309 is produced by immunizing animals with a $\mathrm{Rb}-\mathrm{C}$ fusion protein containing residues 701-928 of human Rb. $\beta$-actin (8H10D10) Mouse mAb \#3700 is produced by immunizing animals with a synthetic peptide corresponding to amino-terminal residues of human $\beta$-actin The cECL Western Blot Kit and SYBR Green Premix detection system were obtained from CoWin Biotech (Beijing, China). All the chemical reagents used were of the highest grade.

\section{Cell culture}

AGS (human gastric carcinoma cells), wild-type EBV positive AGS cell line (AGS-EBV) and wild-type EBVtransformed B-cell lines (lymphoblastoid cell lines, LCL) were obtained from Professor Wenhai Feng (College of Biological Sciences, China Agricultural University, China). GES-1 cell line was purchased from Cancer Institute \& Hospital, Chinese Academy of Medical Sciences (China). Other cell lines used were from Chinese Academy of Sciences (China). Cells were cultured in Ham's F-12 medium (AGS and AGS-EBV cell lines), RPMI 1640 medium (LCL, K562) and DMEM medium (other cell lines) containing $10 \%$ fetal bovine serum, $100 \mathrm{U} / \mathrm{ml}$ penicillin and $100 \mu \mathrm{g} / \mathrm{ml}$ streptomycin at $37{ }^{\circ} \mathrm{C}$ with $5 \% \mathrm{CO}_{2}$. Medium contain DMSO were used as vehicle control.

\section{Cell viability and cytotoxicity assay}

MTT assay was used to determine the cell viabilities after the treatment of tested fractions. AGS, AGS-EBV, HeLa, BGC-823, GES-1 cells $\left(6 \times 10^{3}\right.$ cells/well $)$; WPMY, SV-HUC-1, DU145, PC3 cells $\left(7 \times 10^{3}\right.$ cells/well $)$; A549, HepG-2 cells $\left(8 \times 10^{3}\right.$ cells/well); LCL, K562 cells $\left(9 \times 10^{3}\right.$ cells/well $)$ were seeded in triplicate in 96-well plates and cultured at $37{ }^{\circ} \mathrm{C}$ for $24 \mathrm{~h}$. Cells were treated by different fractions in various concentrations (DMSO, 2.5, 5, 10, 20, $40 \mu \mathrm{g} / \mathrm{mL}$ ). After $24 \mathrm{~h}$ treatments, MTT $(5 \mathrm{mg} / \mathrm{mL}$ ) was added to each well for another $4 \mathrm{~h}$. The medium were then removed and $150 \mu \mathrm{L}$ DMSO was added. The absorbance was measured at $570 \mathrm{~nm}$ using the Microplate Reader (Bio Tek, America). Cell viability was expressed as the ratio of surviving cells in each group to control group. 
Trypan blue exclusion was used to examine the numbers of dead cells in each group. AGS cells and AGSEBV cells $\left(1 \times 10^{6}\right.$ cells/well $)$ were plated in 6 -well plates for $24 \mathrm{~h}$ and then treated with various concentrations of R2 (DMSO, 2.5, 5, 10, 20 and $40 \mu \mathrm{g} / \mathrm{mL}$ ) for $24 \mathrm{~h}, 48 \mathrm{~h}$ and $72 \mathrm{~h}$. After harvesting, the cells were suspended in PBS and mixed with $0.4 \%$ trypan blue solution. The number of viable cells and dead cells were counted under the light microscope.

\section{Detection of apoptotic cells}

Apoptotic cells were detected by Hoechst 33342 staining and Annexin V-PE/7-AAD detection. AGS-EBV cells were cultured in 96-well plates and treated with R2 (DMSO, 5, 10 , and $20 \mu \mathrm{g} / \mathrm{mL}$ ) for $24 \mathrm{~h}$. After washed with PBS, cells were stained with Hoechst $33342(10 \mu \mathrm{g} / \mathrm{mL})$ for $10 \mathrm{~min}$. Morphology changes in nuclear were observed using Image Xpress Micro imaging system (Molecular Devices, USA).

AGS-EBV cells $\left(1 \times 10^{6}\right.$ cells/well $)$ were seeded in 6-well plates for $24 \mathrm{~h}$ and then treated with various concentrations of R2 (DMSO, 5, 10 and $20 \mu \mathrm{g} / \mathrm{mL}$ ) for $24 \mathrm{~h}$. After washing twice with PBS, the cells were stained by an Annexin V-PE/7-AAD apoptosis kit (KeyGEN Biotech, Nanjing, China) according to the manufacturer's instructions. Stained cells were detected and analyzed using flow cytometry (Becton Dickinson, USA).

\section{Detection of mitochondrial membrane potential}

Changes in the mitochondrial membrane potential after R2 treatment were measured by flow cytometry using DIOC $_{6}$. Cells were treated with R2 (DMSO, 5, 10, and $20 \mu \mathrm{g} / \mathrm{mL}$ ) for $24 \mathrm{~h}$. Cells were then harvested and incubated with $\mathrm{DIOC}_{6}(5 \mu \mathrm{M})$ for $30 \mathrm{~min}$ in the dark at $37^{\circ} \mathrm{C}$. After washing with PBS, cells were analyzed by flow cytometry.

\section{Cell cycle analysis}

Cell cycle phase distributions were measured by staining DNA with Propidium Iodide. AGS-EBV cells were seeded in 6-well plates and treated with R2 (DMSO, 5, 10 , and $20 \mu \mathrm{g} / \mathrm{mL}$ ) for 24,48 and $72 \mathrm{~h}$. Then harvested the cell and fixed in $70 \%$ ethanol overnight at $-20{ }^{\circ} \mathrm{C}$. After washing 3 times with PBS, incubated the cells with RNase A (Amresco, USA) for $20 \mathrm{~min}$. Then the cells were stained with $50 \mu \mathrm{g} / \mathrm{mL}$ PI for $10 \mathrm{~min}$ in the dark at room temperature. DNA contents were detected by flow cytometry and analyzed by ModFit LT 4.0.

\section{Western blot}

AGS-EBV and LCL cells were exposed to R2 (DMSO, 5, 10 , and $20 \mu \mathrm{g} / \mathrm{mL}$ ) for $24 \mathrm{~h}$. After collection, cells were lysed in lysis buffer and protein concentrations were determined by BCA method. Protein samples $(40 \mu \mathrm{g})$ were separated by SDS-PAGE gel electrophoresis and electrically transferred onto PVDF membranes. After blocking with $5 \%$ non-fat milk solution for $1 \mathrm{~h}$, the membranes were incubated with primary antibody at $4{ }^{\circ} \mathrm{C}$ overnight. Later, washed away the primary antibody with TBST and incubated with the HRP-conjugated secondary antibody at room temperature for $1 \mathrm{~h}$. The protein bands were visualized by cECL. The level of $\beta$-actin for each sample was used as a control.

RT-PCR detected the expression of specific mRNA related with EBV lytic replication

The changes of mRNA expression after R2 treatment in AGS-EBV cells were quantified by real-time polymerase chain reaction (RT-PCR). AGS-EBV cells were exposed to R2 (DMSO, 5, 10, and $20 \mu \mathrm{g} / \mathrm{mL}$ ) for $24 \mathrm{~h}$. Trizol was used to lysis cells. After RNAs were extracted, we used Nanodrop 2000 (Thermo scientific) to quantity RNA. The sequences of primers were AAATTTAAGAGATCC TCGTGTAAAACATC (sense) and CGCCTCCTGTT GAAGCAGAT (anti-sense) for BZLF1; ATGGAA CATGCGTCGTTG (sense) and AATGGCCACGCTCA ACAT (anti-sense) for BRLF1; CAACACCGCACTG GAGAG (sense) GCCTGCTTCACTTTCTTGG (antisense) for BMRF1, TTGCCATCAATGACCCCTTCA (sense) and CGCCCCACTTGATTTTGGA (anti-sense) for $\beta$-Actin. $\beta$-Actin was served as an internal reference. The mRNA expression levels were measured by SYBR Green Premix detection system (Cwbio, China). The PCR conditions were $95{ }^{\circ} \mathrm{C} 20 \quad$ s; $95{ }^{\circ} \mathrm{C} \quad 3$ s、 $60{ }^{\circ} \mathrm{C}$ $30 \mathrm{~s}$ (40 cycles).

\section{Statistical analysis}

All data were analyzed by IBM SPSS statistics 19 . The differences in the means between groups were compared by $\mathrm{t}$-tests. The statistically significant between groups was defined as ${ }^{* *} p<0.01$ or $* P<0.05$. Results were expressed as mean $\pm \mathrm{SD}$.

\section{Results}

The effects of growth suppression and death induction of trichloromethane fraction of I. compacta Maxim. roots (IC-TCL, R2) in EBV positive human gastric cancer cells (AGS-EBV)

UHPLC-MS chromatogram result of dichloromethane fraction of I. compacta. was showed in Additional file 1: Figure S1. First we used MTT assay to explore the antiproliferative effects of fractions from I. compacta roots against commonly observed cancer cell lines: stomach (AGS, EBV-AGS, BGC-823), liver (HepG-2), leukemia (K562), cervix (HeLa), lung (A549) and prostate (PC3 and DU145) cancer. The cell viabilities and fraction concentrations resulting in $50 \%$ growth inhibition $\left(\mathrm{IC}_{50}\right)$ were showed in Fig. 1b, Table 1 and Table 2 of each 
a

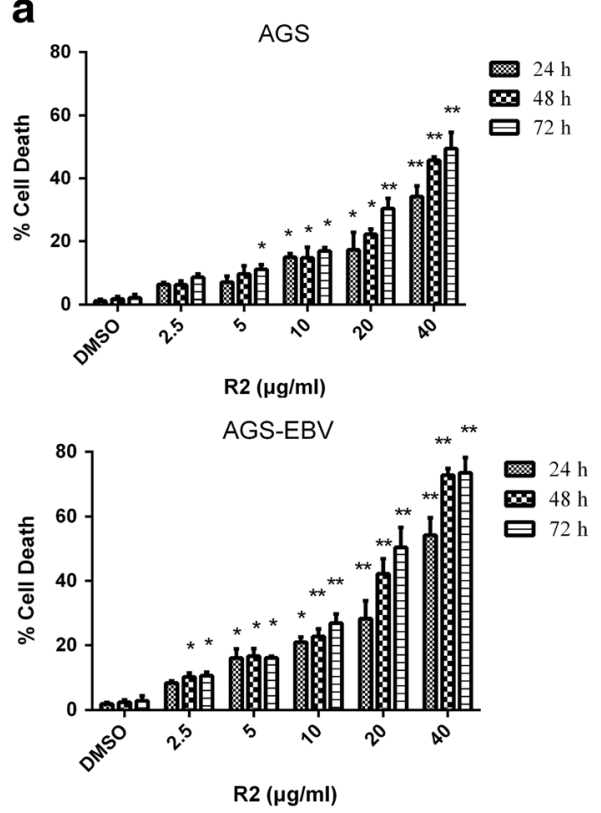

b

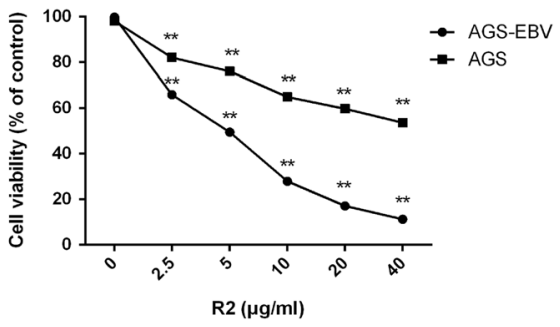

C

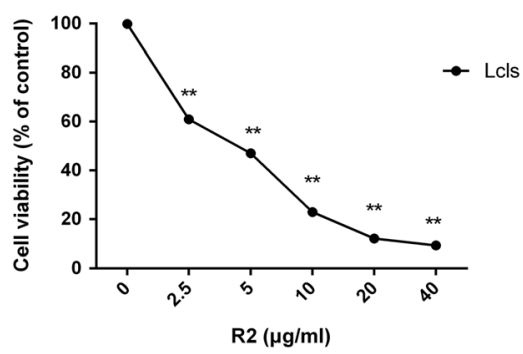

Fig. 1 Inhibition effects of R2 on cell viabilities. Effects of R2 on the viabilities of EBV positive human AGS gastric cancer cells and AGS by trypan blue assay (a) and MTT assay (b). Effects of R2 on the viabilities of EBV-transformed B-cell lines (LCL) (c). Cells were exposed to R2 (0, 2.5, 5, 10, 20, $40 \mathrm{\mu g} / \mathrm{mL}$ ) for $24 \mathrm{~h}, 48 \mathrm{~h}$ or $72 \mathrm{~h}$ for trypan blue assay and $24 \mathrm{~h}$ for MTT assay. R2 suppressed cell viability and induced AGS-EBV and LCL cell death, while being less cytotoxic to AGS cells. The data showed the mean value of three independent tests and were expressed as means \pm SD. ${ }^{*} P<0.05$ and ${ }^{*} P<0.01$ were considered statistically significant

fraction in all cell lines. The $\mathrm{IC}_{50}$ values varied in each cell line for different fractions. R2 showed dosedependent cytotoxic effects in AGS-EBV cancer cells with $\mathrm{IC}_{50}$ of $5.74 \mu \mathrm{g} / \mathrm{mL}$ and $52.24 \mu \mathrm{g} / \mathrm{mL}$ in AGS (Fig. 1b; Table 1). While showed less cytotoxic effects in human normal gastric epithelial cell line GES-1, human normal prostate stromal immortalized cell line WPMY, human normal bladder cell SV-HUC-1 and other cancer cell lines (Table 3). However, other fractions of the roots of the plant showed less cytotoxic effects in all cancer cell lines tested in this research (Table 1 and 2). It indicated that trichloromethane fraction of I. compacta roots (R2) was most effective in inhibiting the proliferation of EBV positive AGS cancer cells.

Then we used trypan blue exclusion to evaluate the cytotoxicity of R2 in AGS and AGS-EBV cells. AGS and AGS-EBV cells were exposure to various concentrations of R2 $(0,2.5,5,10,20,40 \mu \mathrm{g} / \mathrm{mL})$ for $24 \mathrm{~h}, 48 \mathrm{~h}$ and
$72 \mathrm{~h}$. As shown in Fig. 1a, treatment with $10 \mu \mathrm{g} / \mathrm{mL}$ of $\mathrm{R} 2$ for $48 \mathrm{~h}$ and $72 \mathrm{~h}$ resulted in significant effects on cell death in AGS-EBV, while the number of dead cells slightly changed after R2 treatment in AGS cells. Together, these data suggested that R2 can inhibit the growth and induce the death in AGS-EBV cells while less cytotoxic to AGS cells.

Therefore we choose R2 for further investigation to analyze the anti-cancer mechanisms in EBV positive AGS cancer cells.

\section{The effect of growth suppression of R2 in LCL cells}

Since R2 significantly inhibited the growth of AGSEBV cells, we then investigated the effect of $\mathrm{R} 2$ on the viability of EBV-transformed B-cell lines (LCL). LCL cells were treated with different concentrations of R2, and the cell viability was measured by MTT assay. The results showed that the cell viability of

Table $1 I_{50}$ values of different cancer cell lines after treatment with R2

\begin{tabular}{llllll}
\hline Compounds & \multicolumn{1}{l}{ IC50 $(\mu \mathrm{M})^{\mathrm{a}}$} & & & \\
\cline { 2 - 5 } & AGS & AGS-EBV & LCL & HepG2 & $39.73 \pm 2.92$ \\
\hline IC-TCL & $52.24 \pm 3.01$ & $5.64 \pm 1.14$ & $5.12 \pm 1.66$ & $31.57 \pm 3.29$ \\
IC-BT & $94.74 \pm 3.53$ & $29.57 \pm 2.33$ & $42.37 \pm 5.31$ & $64.23 \pm 2.76$ & $>200$ \\
IC-R & $163.62 \pm 3.85$ & $68.73 \pm 2.12$ & $>200$ & $79.58 \pm 4.32$ & $96.18 \pm 4.67$
\end{tabular}

${ }^{\mathrm{a}} \mathrm{C}_{50}$ is the concentration of compound causing $50 \%$ growth inhibition in each cell line. The results showed the mean values of three independent tests 
Table $2 \mathrm{IC}_{50}$ values of different cancer cell lines after treatment with R2

\begin{tabular}{llllll}
\hline Compounds & \multicolumn{1}{l}{ IC50 $(\mu \mathrm{M})^{\mathrm{a}}$} & & & \\
\cline { 2 - 6 } & HeLa & K562 & A549 & DU145 & BGC-823 \\
\hline IC-TCL & $54.26 \pm 3.18$ & $27.47 \pm 2.06$ & $19.96 \pm 3.28$ & $50.51 \pm 3.98$ & $90.24 \pm 2.57$ \\
IC-BT & $43.27 \pm 2.23$ & $38.53 \pm 1.97$ & $>200$ & $82.73 \pm 1.62$ & $34.78 \pm 2.61$ \\
IC-R & $85.96 \pm 3.21$ & $>200$ & $76.53 \pm 2.26$ & $37.51 \pm 1.77$ & $54.13 \pm 2.74$ \\
\hline
\end{tabular}

${ }^{\mathrm{a}} \mathrm{C}_{50}$ is the concentration of compound causing $50 \%$ growth inhibition in each cell line. The results showed the mean values of three independent tests

LCL decrease in a dose-dependent manner. Cell viability reduced by $40 \%$ at $2.5 \mu \mathrm{g} / \mathrm{mL}$ and further reduced by $80-90 \%$ at $20 \mu \mathrm{g} / \mathrm{mL}$ R2 treatment (Fig. 1c).

Apoptosis evaluation using Hoechst staining and Annexin V-PE/7-AAD assay after R2 treatment in AGS-EBV cells

To elucidate whether the cytotoxic effect of R2 was associated with apoptosis induction, we used Hoechst 33342 and Annexin V-PE/7-AAD staining to explore the morphological changes and the numbers of apoptotic cells after $\mathrm{R} 2$ treatment. Based on $\mathrm{IC}_{50}$ value, we used $5 \mu \mathrm{g} / \mathrm{mL}, 10 \mu \mathrm{g} / \mathrm{mL}$ and $20 \mu \mathrm{g} / \mathrm{mL}$ of $\mathrm{R} 2$ as treatment concentrations in AGS-EBV cells. In Hoechst 33342 staining, typical morphological change of apoptosis as condensed chromatin was observed when cells were exposure to R2 (Fig. 2a). In Annexin V-PE/7-AAD assay, the population of apoptotic cells $(\mathrm{AV}+/ 7-\mathrm{AAD}$ - plus $\mathrm{AV}$ $+/ 7-\mathrm{AAD}+$ ) increased in a dose-dependent manner (Fig. $2 \mathrm{~b}$ and $\mathrm{c}$ ) when compared with vehicle group.

These observations indicated that the proliferation inhibition effect of R2 in AGS-EBV cells may be related with apoptosis induction.

\section{Effect of R2 on mitochondrial membrane potential in AGS-EBV cells}

Apoptosis is also marked by the decrease of mitochondrial membrane potential. DIOC $_{6}$ is often used as an indicator to detect $\Delta \psi$ during apoptosis. To further confirm the induction of apoptosis, we then analyzed the changes of mitochondrial membrane potential in AGS-EBV cells. As showed in Fig. 3a and b, R2 treatments induced significant increase of green fluorescence from $9.5 \%$ to $30.93 \%$, indicating the loss of $\Delta \psi$. These results further showed that the anti-proliferation effect of $\mathrm{R} 2$ is associated with the induction of apoptosis. $\mathrm{DIOC}_{6}$ fluorescence was mostly appeared in red indicated that the majority cells were alive in control group.

Table $3 I_{50}$ values of different normal cell lines after treatment with R2

\begin{tabular}{llll}
\hline Compounds & \multicolumn{1}{l}{ IC50 $(\mu \mathrm{M})^{\mathrm{a}}$} & & \\
\cline { 2 - 4 } & GES-1 & WPMY & SV-HUC-1 \\
\hline IC-TCL & $83.57 \pm 2.46$ & $>200$ & $97.65 \pm 5.21$ \\
\hline
\end{tabular}

${ }^{\mathrm{a}} \mathrm{C}_{50}$ is the concentration of compound causing $50 \%$ growth inhibition in each cell line. The results showed the mean values of three independent tests
Effects of R2 on the expression of apoptosis and cell cycle regulation-related proteins in AGS-EBV cells

The Bcl-2 family proteins are critical regulators of apoptosis at the mitochondria and endoplasmic reticulum [23]. Since the results showed that R2 induce apoptosis in AGS-EBV cells, we then analyzed the expression of Bax and $\mathrm{Bcl}-2$ proteins after treated with $\mathrm{R} 2$. Western blot results showed Bax protein increased while Bcl-2 protein decreased after treatment (Fig. 4). These results indicated that the apoptosis activated by $\mathrm{R} 2$ was related with $\mathrm{Bcl}-2$ family proteins.

To gain further understanding about the molecular mechanisms of cell cycle arrest in AGS-EBV cells, we analyzed the effects of R2 on the expression of G0/G1 phase regulatory proteins. Figure 4 showed that after treatment with $\mathrm{R} 2$, the expression of cyclin D1 decreased, while the expression of $\mathrm{Rb}$ increased. These results suggested that the changes of protein expression may play important roles in G0/G1 arrest of cell cycle in AGS-EBV cells.

\section{Effects of R2 on EBV lytic mRNAs expression in AGS-EBV cells}

To further study the effects of R2 on EBV lytic induction, we performed RT-PCR to investigate the expression of essential lytic genes after R2 treatment. AGS-EBV cells were exposed to R2 (DMSO, 5, 10 and $20 \mu \mathrm{g} / \mathrm{mL}$ ), then the expression levels of immediate early lytic genes (BZLF1 and BRLF1) and early lytic gene (BMRF1) of EBV were tested. As shown in Fig. 5a, the mRNAs expression level of BZLF1, BMRF1 and BRLF1 were increased in AGS-EBV cell line after R2 treatment.

\section{Effects of R2 on EBV lytic proteins expression in AGS-EBV and $L C L$ cells}

We further analyzed the effects of R2 induced the expression of EBV lytic protein BMRF1 and BZLF1 in both AGS-EBV and LCL cells. The two proteins were required for viral polymerase process and essential for lytic EBV replication [11]. As showed, the expression of BMRF1 and BZLF1 in both AGS-EBV (Fig. 5b) and LCL (Fig. 5d) cells increased after R2 treatment. As EBV lytic was a cascade reaction, the expression of BMRF1 and BZLF1 were not exactly the same. 
a

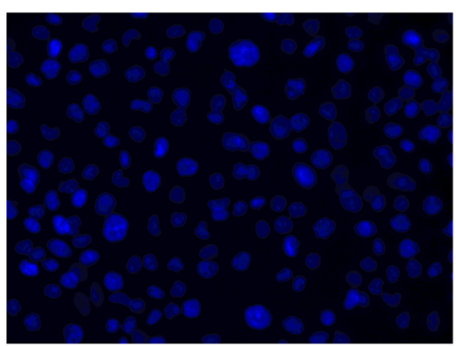

Control

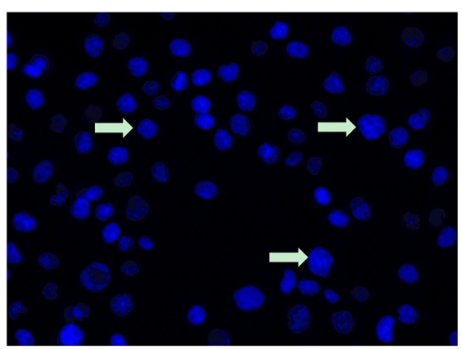

b

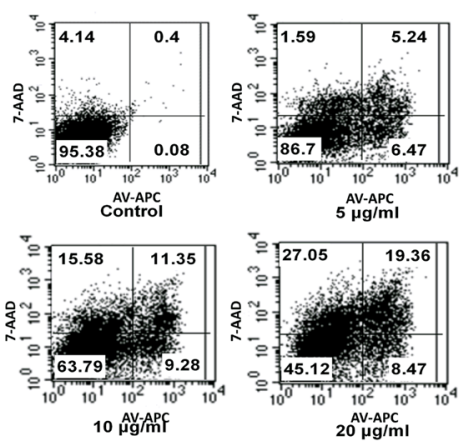

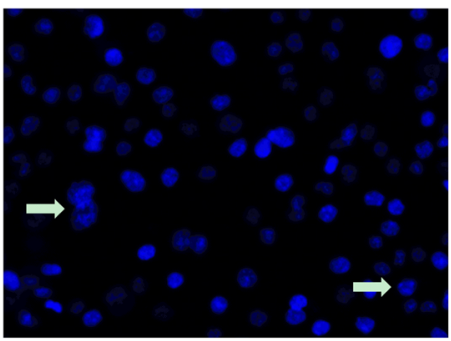

$5 \mu \mathrm{g} / \mathrm{ml}$

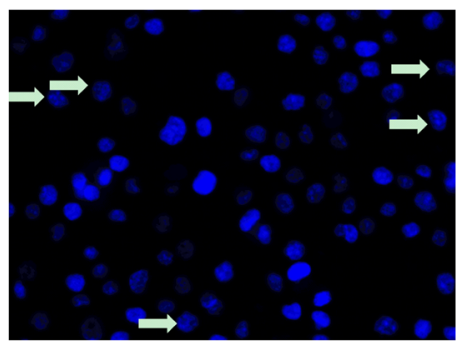

$20 \mu \mathrm{g} / \mathrm{ml}$

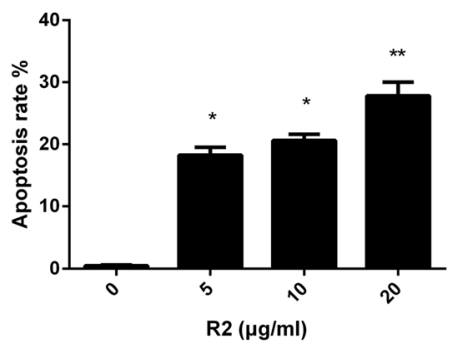

Fig. 2 Induction of apoptosis after R2 treatment in AGS-EBV cells. Micrographs show apoptotic cells after treatment with R2 at different concentrations and staining by Hoechst 33342 for $24 \mathrm{~h}$ (a). R2 induced apoptosis in AGS-EBV cells was also detected by the Annexin V-FITC/7-AAD staining test (b and $\mathbf{c}$ ). Cells were treated with R2 $(0,5,10,20 \mathrm{\mu g} / \mathrm{mL})$ for $24 \mathrm{~h}$. DMSO treatment was used as a vehicle control. The apoptotic rates were determined by Annexin V-FITC/7-AAD staining. ${ }^{*} P<0.05$ and ${ }^{* *} P<0.01$ were considered statistically significance

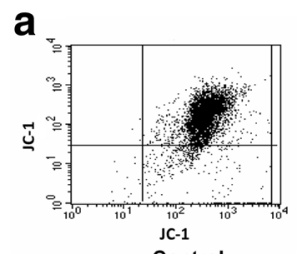

Control

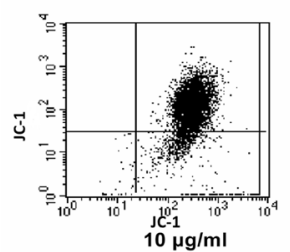

$10 \mu \mathrm{gg} / \mathrm{ml}$

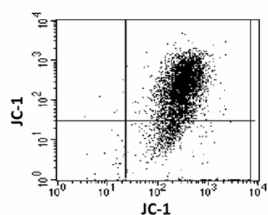

$5 \mu \mathrm{g} / \mathrm{ml}$

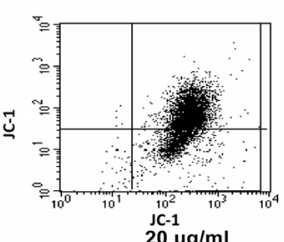

b

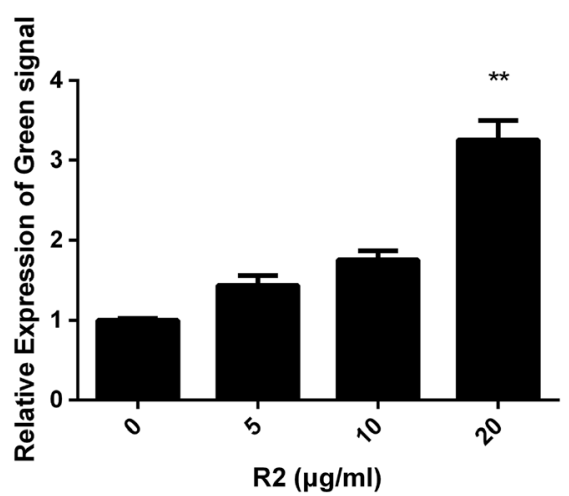

Fig. 3 R2 induced mitochondrial membrane potential depolarization (a and $\mathbf{b}$ ) in AGS-EBV cells. AGS-EBV cells were cultured in R2 (0, 5, 10, $20 \mathrm{\mu g} / \mathrm{mL}$ ) for $24 \mathrm{~h}$. DMSO treatment was used as vehicle control. Cells were labeled with DIOC6 and then analyzed by flow cytometry to detect the levels of mitochondrial membrane potential. Relative expression levels were showed in $\mathbf{b}$. Results obtained from a representative experiment are shown $(n=3) .{ }^{* *} p<0.01$ was considered statistically significant 


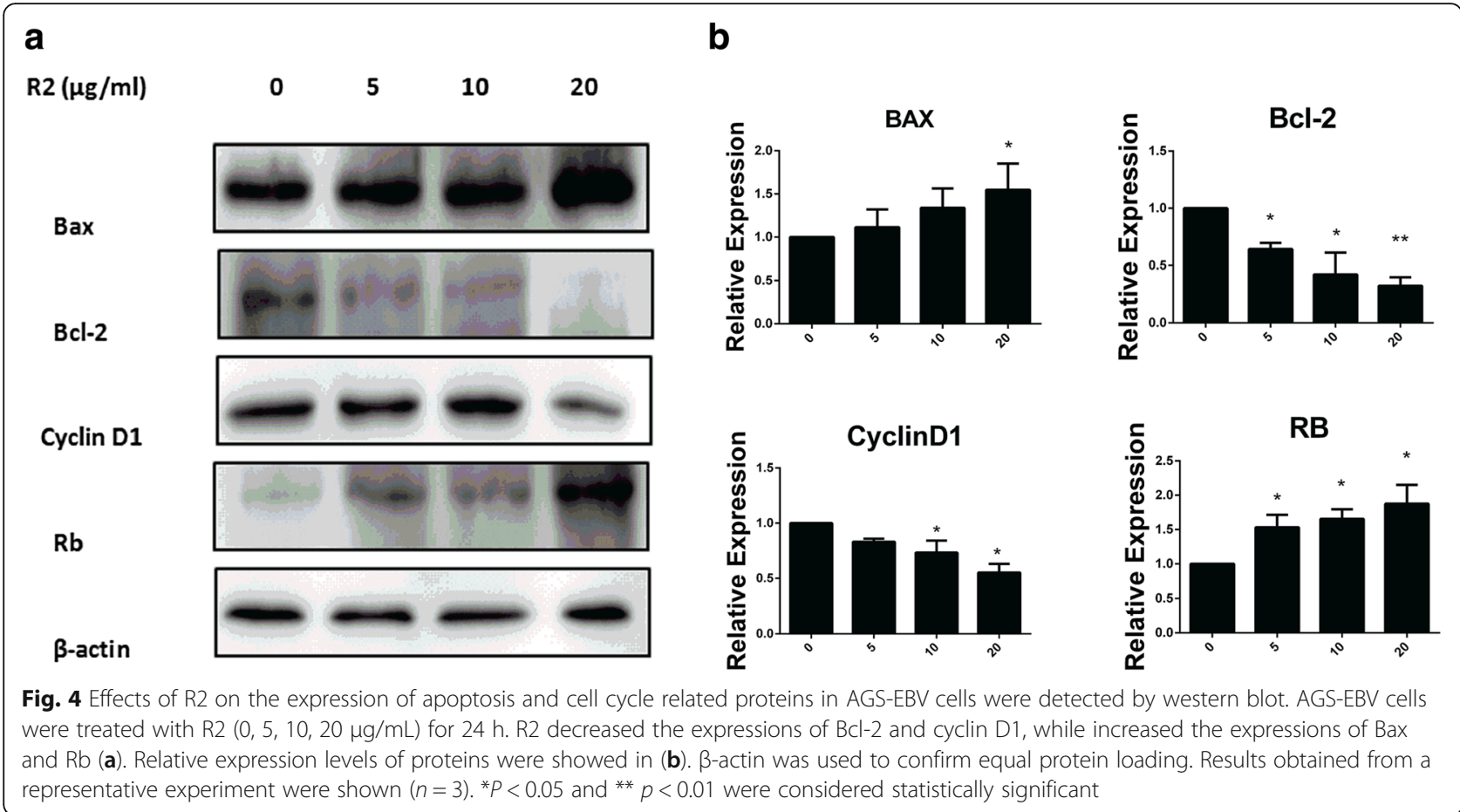

\section{Evaluation of cell cycle arrest in AGS-EBV cells after R2 treatment}

As R2 showed effects on EBV lytic induction, growth inhibition and apoptosis induction in AGS-EBV cells, we explored its effect on cell cycle arrest. AGS-EBV cells were treated with $\mathrm{R} 2$ for $24 \mathrm{~h}, 48 \mathrm{~h}$ and $72 \mathrm{~h}$ before flow cytometry analysis. $48 \mathrm{~h}$ treatment groups showed G0/G1 phase arrest compared with control groups (Fig. 6b). Similar results were obtained in $24 \mathrm{~h}$ treatment group, with a slightly lower number of cells arrested in G0/G1 phase (Fig. 6a). For $72 \mathrm{~h}$ treatment group, the number of apoptosis cells increased compared with other $24 \mathrm{~h}$ and $48 \mathrm{~h}$ groups (Fig. 6c). The distributions of AGS-EBV in cell cycle treated by $\mathrm{R} 2$ for $48 \mathrm{~h}$ were showed in Fig. 6d. These results suggested the induction of G0/G1 arrest in cell cycle may be a factor of growth inhibition and apoptosis induction in AGS-EBV cells after R2 treatment.

\section{Discussion}

Medicinal plants have played important roles in anticancer drug discovery [24]. Incarvillea compacta Maxim. is a perennial herb mainly distributed in Tibet and has been for treating stomach disorder for centuries. In the current study, we investigated the anti-cancer effects of I. compacta extracts in stomach (AGS, AGS-EBV, BGC823), LCL, liver (HepG2), leukemia (K562), cervix (HeLa), lung (A549) and prostate (PC3 and DU145) cancer cells. Cytotoxicity studies showed that trichloromethane fraction (R2) possess cell viability inhibition effects in EBV positive cancer cells (AGS-EBV) and wild-type EBV-transformed B-cell lines (LCL) among all the other fractions and other cancer cell lines.

Since R2 showed different inhibition effects on AGS cells and EBV positive AGS cells, we take further investigations on R2. Gastric cancer has been reported to be associated with EBV [31]. EBV persists in EBV positive malignancies as latent form. Entry into the viral lytic cycle is initiated by the expression of two immediate early EBV proteins and one early protein: Zta encoded by BZLF1, and Rta encoded by BRLF1, EAD encoded by BMRF1 [6, 30]. In this study, we explored the ability of R2 inducing EBV lytic cycle in EBV-positive AGS cell lines and critically examined the relationship between viral lytic cycle activation and the induction of apoptosis in AGS-EBV. R2 could potently induce EBV lytic cycle in AGS-EBV and LCL cells. The mRNA expression levels of immediate early (BZLF1 and BRLF1) and early (BMRF1) lytic genes increased in AGS-EBV cells. Western blot and immunofluorescent staining assays showed the BZLF1 and BMRF1 lytic proteins were increased after R2 treatment in both AGS-EBV and LCL cells. These results indicated that R2 was capable of inducing EBV lytic replication in EBV-positive cancer cells.

Our results were consisting with others that the induction of EBV lytic cycle could mediate additional killing of EBV-positive cancer cells [32, 33] We also observed similar phenomenon in AGS-EBV cells after R2 treatment. Hoechst 33342 staining, mitochondrial membrane potential assay and Annexin V-PE/7-AAD 


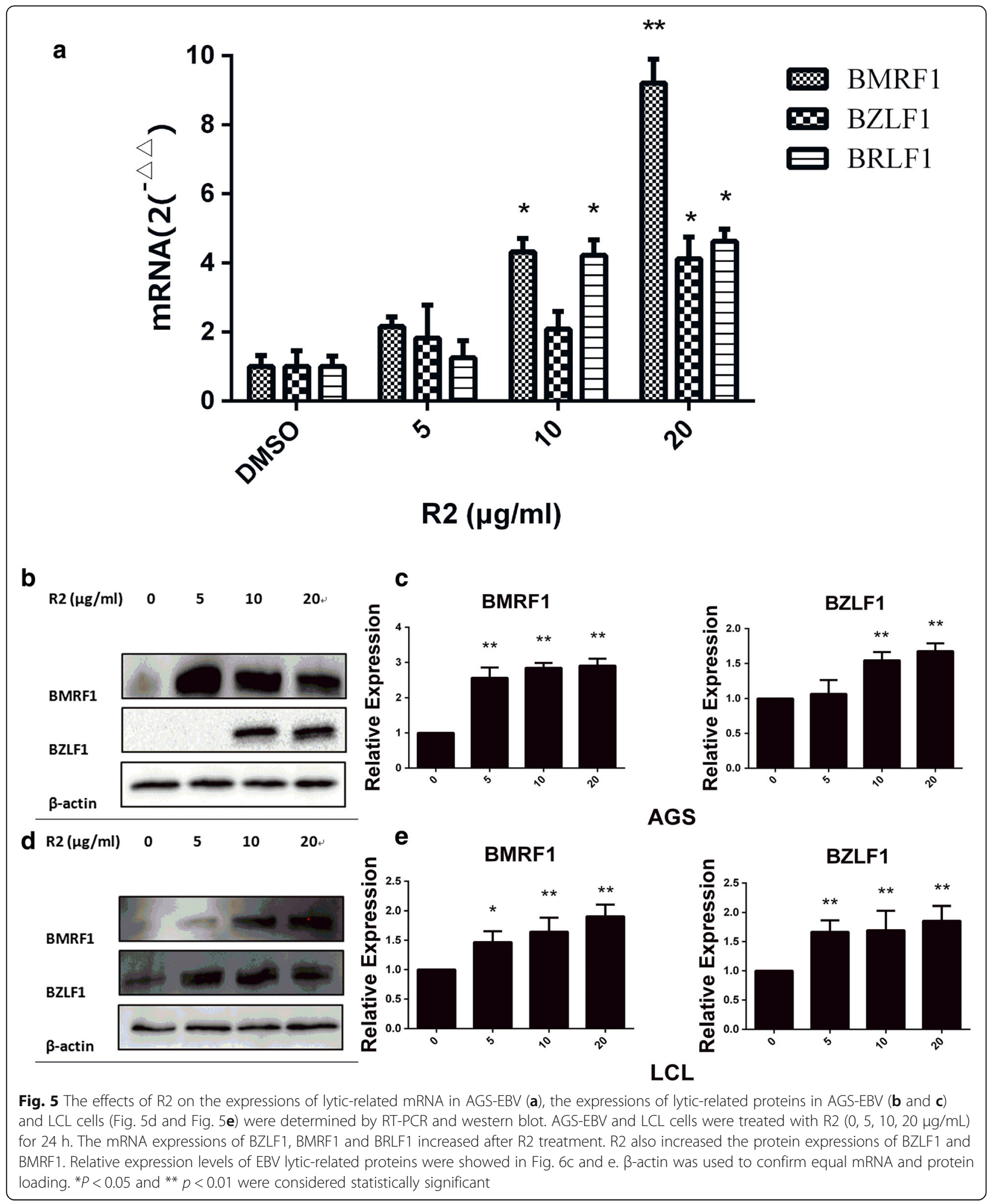

assay for apoptosis revealed that R2 could induce apoptosis in AGS-EBV cells. Western blot results showed the expression of Bax increased, while Bcl-2 decreased. Cell cycle arrest is associated with cell death; however which is not the only factor related to cell death. As in our observations, $10 \mu \mathrm{g} / \mathrm{ml}$ of $\mathrm{R} 2$ could induce G0/G1 cell cycle arrest, which may be at least partly related to the cell death of AGS-EBV. Other treatments like 

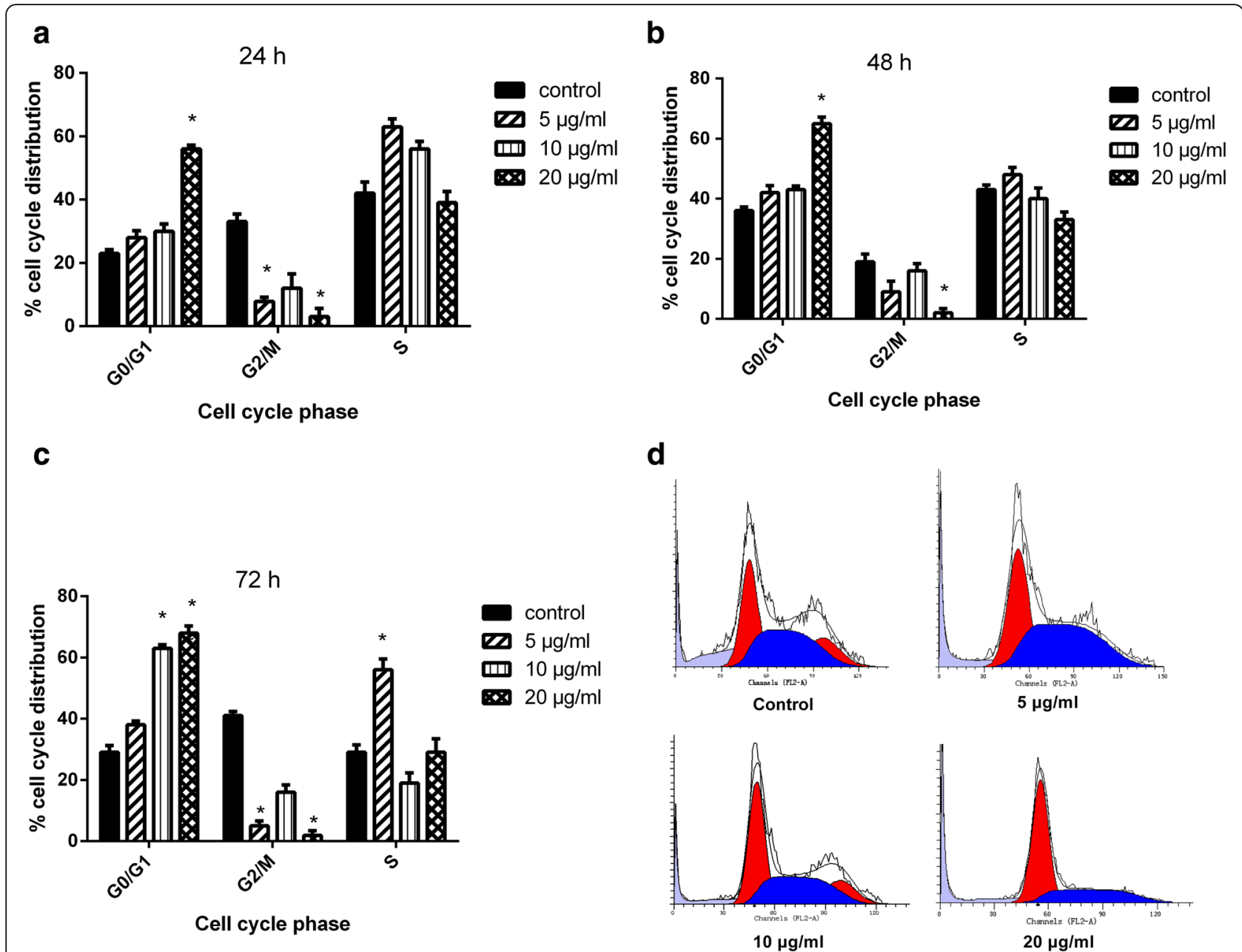

Fig. 6 Effects of R2 on cell cycle progression in AGS-EBV cells. Cells were treated by R2 (0, 5, 10, $20 \mu \mathrm{g} / \mathrm{mL})$ for $24 \mathrm{~h}, 48 \mathrm{~h}, 72 \mathrm{~h}$ and then analyzed by flow cytometry for cell cycle distribution. Cell cycle distributions after $24 \mathrm{~h}(\mathbf{a}), 48 \mathrm{~h}(\mathbf{b}$ and $\mathbf{d})$ and $72 \mathrm{~h}(\mathbf{c})$ treatments in AGS-EBV cells were shown. Results obtained from a representative experiment were shown $(n=3) .{ }^{*} P<0.05$ when compared with the control group

suberoylanilide hydroxamic acid could induce G2/M arrest and enhanced cell death in EBV positive AGS cells had also been reported [32]. We found that cell cycle related proteins cyclin D1 decreased, while the expression of $\mathrm{Rb}$ increased after $\mathrm{R} 2$ treatment. Our results also suggested that R2 treatment exhibit less cytotoxic effects on normal cells and other kinds of cancer cells. Further studies of R2 in other EBV positive cancer cell lines such as SNU-719 are required to explore the mechanism and find the molecular target during this process.

\section{Conclusion}

The current research demonstrated that trichloromethane fraction from Incarvillea compacta Maxim. roots (R2) inhibit the proliferation of EBV-positive AGS cancer cells by inducing EBV lytic replication, apoptosis and cell cycle G0/G1 arrest, through the regulation of related proteins. Therefore, R2 could be treated as a valuable candidate for further investigation as a possible antitumor agent targeting EBV for gastric cancer therapy.

\section{Additional file}

Additional file 1: Figure S1. UHPLC-MS chromatogram profile of dichloromethane fraction of I. compacta. (DOCX $23 \mathrm{~kb}$ )

\section{Acknowledgments}

We would like to thank Professor Wenhai Feng (College of Biological Sciences, China Agricultural University, China) for providing AGS, wild-type EBV positive AGS (AGS-EBV) and wild-type EBV-transformed B-cell lines (lymphoblastoid cell lines, LCL).

\section{Funding}

This work was financially supported by the Ministry of Science and Technology of the People's Republic of China, and Major Scientific and Technological Special Project for "Significant New Drugs Formulation" (Grant No. 2012ZX09501001-004 and 2012ZX09301-002-001-026). This work was also supported by the Program for Innovative Research Team in IMPLAD (PIRTI) and Beijing Key Laboratory of Innovative Drug Discovery of Traditional Chinese 
Medicine (Natural Medicine) and Translational Medicine, Institute of Medicinal Plant Development, Peking Union Medical College and Chinese Academy of Medical Sciences.

\section{Availability of data and materials}

Available.

\section{Authors' contributions}

LC, GS and XS designed the experiments; HW and XX identified the plant material and get these fractions. $L Z$ performed the experiments, analyzed the data and wrote the manuscript. All authors reviewed the manuscript and approved it for submission.

\section{Competing interests}

The authors declare that there is no conflict of interest.

\section{Consent to publication}

Not applicable.

\section{Ethics approval and consent to participate}

Not applicable.

Received: 9 February 2016 Accepted: 31 August 2016

\section{Published online: 05 September 2016}

\section{References}

1. Kanda M, Kodera Y. Recent advances in the molecular diagnostics of gastric cancer. World J Gastroenterol. 2015:21:9838-52.

2. Lordick F, Kang YK, Chung HC, et al. Capecitabine and cisplatin with or without cetuximab for patients with previously untreated advanced gastric cancer (EXPAND): a randomised, open-label phase 3 trial. Lancet Oncol. 2013;14:490-9.

3. Tebbutt N, Price TJ, Sjoquist KM, et al. Final results of AGITG ATTAX3 study: Randomized phase II study of weekly docetaxel (T), cisplatin, and fluoropyrimidine (F) with or without panitumumab (P) in advanced esophagogastric (OG) cancer. J Clin Oncol. 2013;31:4081.

4. Yi JH, Lee J, Lee J, et al. Randomised phase II trial of docetaxel and sunitinib in patients with metastatic gastric cancer who were previously treated with fluoropyrimidine and platinum. Brit J Cancer. 2012;106:1469-74.

5. Kume T, Shinohara T, Takeo H, Yamashita Y, Shirakusa T, Kikuchi M. Low rate of apoptosis and overexpression of bcl-2 in Epstein-Barr virus-associated gastric carcinoma. Histopathology. 1999;34:7.

6. Zauner L, Melroe GT, Sigrist JA, et al. TLR9 triggering in Burkitt's lymphoma cell lines suppresses the EBV BZLF1 transcription via histone modification. Oncogene. 2010;29:4588-98.

7. Feng WH, Israel B, Raab-Traub N, Busson P, Kenney SC. Chemotherapy induces lytic EBV replication and confers ganciclovir susceptibility to EBVpositive epithelial cell tumors. Cancer Res. 2002;62:1920-6.

8. Fu DX, Tanhehco Y, Chen J, et al. Bortezomib-induced enzyme-targeted radiation therapy in herpesvirus-associated tumors. Nat Med. 2008;14:1118-22

9. Perrine SP, Hermine $O, S$ mall $T$, et al. A phase $1 / 2$ trial of arginine butyrate and ganciclovir in patients with Epstein-Barr virus-associated lymphoid malignancies. Blood. 2007:109:2571-8

10. Landais $E$, Saulquin $X$, Scotet $E$, et al. Direct killing of Epstein-Barr virus (EBV)-infected B cells by CD4 T cells directed against the EBV lytic protein BHRF1. Blood. 2004;103:1408-16.

11. Feng $\mathrm{WH}$, Kenney SC. Valproic acid enhances the efficacy of chemotherapy in EBV-positive tumors by increasing lytic viral gene expression. Cancer Res. 2006;66:8762-9.

12. Liu SF, Wang H, Li ZJ, et al. Aspirin induces lytic cytotoxicity in Epstein-Barr virus-positive cells. Eur J Pharmacol. 2008;589:8-13.

13. Jung EJ, Lee YM, Lee BL, Chang MS, Kim WH. Lytic induction and apoptosis of Epstein-Barr virus-associated gastric cancer cell line with epigenetic modifiers and ganciclovir. Cancer Lett. 2007:247:77-83.

14. Hui KF, Cheung AK, Choi CK, et al. Inhibition of class I histone deacetylases by romidepsin potently induces Epstein-Barr virus lytic cycle and mediates enhanced cell death with ganciclovir. Int J Cancer. 2016;138:125-36.

15. Zorofchian Moghadamtousi S, Karimian $\mathrm{H}$, Rouhollahi E, Paydar M, Fadaeinasab M, Abdul KH. Annona muricata leaves induce $G(1)$ cell cycle arrest and apoptosis through mitochondria-mediated pathway in human HCT-116 and HT-29 colon cancer cells. J Ethnopharmacol. 2014;156:277-89.

16. Newman DJ, Cragg GM. Natural products as sources of new drugs over the 30 years from 1981 to 2010. J Nat Prod. 2012;75:311-35.

17. Yang Y. Handbook of Tibetan medicine. Xining: Qinghai People's Press; 1991.

18. Lu L, Yang M, Lin S, Zheng Q, Zhang W. Chemical constituents from acetyl acetate extract fraction of Incarvillea delavayi. Zhongguo Zhong Yao Za Zhi. 2009;34:1799-801.

19. Huang Z, Zhang W, Lin S, et al. Chemical constituents from roots of Incarvillea mairei. Zhongguo Zhong Yao Za Zhi. 2009;34:1672-5.

20. Yu ZW, Zhu HY, Yang XS, Sun QY, Hao XJ. Study on chemical constituents from Incarvillea arguta and their accelerating PC-12 cell differentiation. Zhongguo Zhong Yao Za Zhi. 2005:30:1335-8.

21. Chen YQ, Zhang WD, Kong LY, Lu T, Shen YH. Delavayol, a novel sesquiterpene from Incarvillea delavayi Bureau et Franchet. Nat Prod Res. 2010;24:915-9.

22. Ting $\mathrm{S}$, Xue L, Wei $H$, et al. Hepatoprotective effect of phenylethanoid glycosides from Incarvillea compacta against CCl4-induced cytotoxicity in HepG2 cells. J Korean Soc Appl Biol Chem. 2015;58:617-25.

23. Susnow N, Zeng L, Margineantu D, Hockenbery DM. Bcl-2 family proteins as regulators of oxidative stress. Semin Cancer Biol. 2009;19:42-9.

24. Younes RN, Varella AD, Suffredii IB. Discovery of new antitumoral and antibacterial drugs from brazilian plant extracts using high throughput screening. Clinics (Sao Paulo). 2007;62:763-8.

25. Pan WG, Jiang SP, Luo $P$, Gao $P$, Chen $B, B$ B HT. Extracts from the roots of Incarvillea younghusbandii on antioxidant effects and life span prolonging in Drosophila melanogaster. Chin J Nat Med. 2012;10:48-52.

26. Lim do $\mathrm{Y}$, Lee $\mathrm{MH}$, Shin $\mathrm{SH}$, et al. (+)-2-(1-Hydroxyl-4-oxocyclohexyl) ethyl caffeate suppresses solar UV-induced skin carcinogenesis by targeting PI3K, ERK1/2, and p38. Cancer Prev Res. 2014;7:856-65.

27. Woellmer A, Arteaga-Salas JM, Hammerschmidt W. BZLF1 governs CpGmethylated chromatin of Epstein-Barr Virus reversing epigenetic repression. PLoS Pathog. 2012:8:e1002902.

28. Puccini J, Kumar S. Caspases. In: Bradshaw RA, Stahl PD, editors. Encyclopedia of Cell Biology. Waltham: Academic; 2016. p. 364-73.

29. Zhang Q, Hong Y, Dorsky D, et al. Functional and physical interactions between the Epstein-Barr virus (EBV) proteins BZLF1 and BMRF1: Effects on EBV transcription and lytic replication. J Virol. 1996;70:5131-42.

30. Furnari FB, Adams MD, Pagano JS. Regulation of the Epstein-Barr virus DNA polymerase gene. J Virol. 1992;66:2837-45.

31. lizasa H, Nanbo A, Nishikawa J, Jinushi M, Yoshiyama H. Epstein-Barr Virus (EBV)-associated gastric carcinoma. Viruses. 2012;4:3420-39.

32. Hui KF, Chiang AK. Suberoylanilide hydroxamic acid induces viral lytic cycle in Epstein-Barr virus-positive epithelial malignancies and mediates enhanced cell death. Int J Cancer. 2010;126:2479-89.

33. Liu S, Li H, Chen L, et al. (-)-Epigallocatechin-3-gallate inhibition of Epstein-Barr virus spontaneous lytic infection involves ERK1/2 and PI3-K/Akt signaling in EBV-positive cells. Carcinogenesis. 2013;34:627-37.

\section{Submit your next manuscript to BioMed Central and we will help you at every step:}

- We accept pre-submission inquiries

- Our selector tool helps you to find the most relevant journal

- We provide round the clock customer support

- Convenient online submission

- Thorough peer review

- Inclusion in PubMed and all major indexing services

- Maximum visibility for your research

Submit your manuscript at www.biomedcentral.com/submit
C) BioMed Central 